\title{
Growing-season rainfall and scenarios of future change in southeast Africa: implications for cultivating maize
}

\author{
Mark Tadross ${ }^{1, *}$, Pablo Suarez ${ }^{2}$, Alex Lotsch ${ }^{3}$, Sepo Hachigonta ${ }^{1}$, Marshall Mdoka ${ }^{1}$, \\ Leonard Unganai ${ }^{4}$, Filipe Lucio ${ }^{5}$, Donald Kamdonyo ${ }^{6}$, Maurice Muchinda ${ }^{7}$ \\ ${ }^{1}$ Climate Systems Analysis Group, Department of Environmental \& Geographical Science, University of Cape Town, \\ Rondebosch 7701, South Africa \\ ${ }^{2}$ Red Cross/Red Crescent Climate Centre, Leeghwaterplein 27, 2521 CV Den Haag, The Netherlands \\ ${ }^{3}$ Commodity Risk Management Group, Agriculture and Rural Development, World Bank, 1818 H Street, Washington, DC, USA \\ ${ }^{4}$ National Meteorological Service of Zimbabwe, PO Box BE150, Belvedere, Harare, Zimbabwe \\ ${ }^{5}$ Instituto Nacional de Meteorologia, Rua de Mukumbura 164, C. P. 256, Maputo, Mozambique \\ ${ }^{6}$ National Meteorological Service of Malawi, Llilongwe, Malawi \\ ${ }^{7}$ National Meteorological Service of Zambia, Lusaka, Zambia
}

\begin{abstract}
Global climate change is a detectable and attributable global phenomenon, yet its manifestation at the regional scale, especially within the rainfall record, can be difficult to identify. This problem is particularly acute over southern Africa, a region characterised by a low density of observations and highly dependent on rural agriculture, where the impact of rainfall changes on maize cultivation critically depends on the timing with respect to the crop phenological cycle. To evaluate changes in rainfall affecting maize cropping, daily rainfall observations from 104 stations across Malawi, Mozambique, Zambia and Zimbabwe were used to detect trends in planting dates, rainfall cessation and duration of the rainfall season, as well as number of dry days, length of dry spells and measures of rainfall intensity during critical periods for growing maize. Correlations with the Southern Oscillation Index (SOI) and Antarctic Oscillation (AAO) were used to infer how large-scale climate variability affects these attributes of rainfall and highlight where (and when) trends may contribute to more frequent crossings of critical thresholds. The El Niño Southern Oscillation (ENSO) was associated with changes in planting and cessation dates as well as the frequency of raindays during the rainfall season (particularly early in the season). AAO mainly affected raindays towards the end of the season when maize was planted late. Trends are discussed relative to changes projected in empirically downscaled scenarios of rainfall from 7 general circulation models for the 2046-2065 period, assuming an SRES A2 emissions scenario.
\end{abstract}

KEY WORDS: Rainfall · Maize $\cdot$ Crops $\cdot$ Africa $\cdot$ Climate change $\cdot$ Downscaling

Resale or republication not permitted without written consent of the publisher

\section{INTRODUCTION}

Africa is highly vulnerable to climate change, largely because many socioeconomic activities in Africa, particularly agriculture, depend on climate and especially rainfall. Within the agriculture sector, drought is arguably the most important climatic challenge and has major impacts on rural livelihoods (Buckland et al. 2000). During the 1991-1992 drought, cereal output in the Southern African Development Community (SADC) region (excluding South Africa, but including Zimbabwe, Zambia, Malawi and Mozambique) fell from an average of 11.3 million to 6.2 million $t$, necessitating extensive food imports (FAO 2004). Furthermore, southern Africa's agriculture sector is particularly vulnerable to climate change, with potentially negative impacts on revenue from dryland farming (Kurukulasuriya et al. 2006). There is therefore a press- 
ing need to assess the capacity of southern African countries to cope with, and adapt to, the impact of climate change within the agriculture sector.

One major problem for any climate adaptation initiative, particularly at the local level, is insufficient information about what to adapt to. This often results from a lack of awareness of how the climate has changed in the past, how it is expected to change in the future and if observed changes are consistent with projected changes based on models of the climate system (e.g. Jones et al. 2004, Tadross et al. 2005b, Hewitson \& Crane 2006). Complications may also arise when attempting to relate changes in monthly or seasonal averages to impacts in a particular sector. For the agricultural sector, it is crucial to know how rainfall characteristics which affect planting dates and the crop growth cycle (Dennett 1987, Ati et al. 2002, Usman et al. 2005) may be changing.

Besides long-term change, year-to-year variability and its effect on farm management decisions is also crucial. The superposition of this shorter-term climate variability on longer term change, within a region that operates close to critical thresholds, is key to formulating adequate adaptation options. Whilst aspects of year-to-year climate variability, such as the El Niño Southern Oscillation (ENSO) and Antarctic Oscillation (AAO), have a well-documented relationship with seasonal climate anomalies in the region (e.g. Lindesay 1988, Mason 1995, Richard et al. 2000, Hulme et al. 2001, Reason \& Rouault 2005), relatively fewer studies have investigated relationships with rainfall characteristics that are closely tied to management decisions and the crop growth cycle (e.g. Usman \& Reason 2004 Reason et al. 2005, Tadross et al. 2005a). Certainly, within southern Africa little is currently known regarding how trends (see New et al. 2006) and variability combine to affect daily rainfall characteristics at the local level and the potential impacts on crops.

The present study explored observed changes in daily rainfall records and evaluated the agricultural implications of these changes by calculating indices that can be directly related to farm management decisions and impacts on crop growth. These indices, based on the frequency and intensity of rainfall, were developed to represent planting dates, rainfall cessation, dry spell length, frequency of dry days, rainfall intensity and total rainfall during critical stages of the crop growth cycle. As maize is the main SADC food/nutrition source (Smale \& Jayne 2003), we tailored these indices to be relevant for growing maize. To understand how variations in these indices (and the suggested impact on maize cropping) are linked to large-scale climate modes, we correlated them to ENSO and AAO and calculated trends using daily rainfall data from 104 stations across Malawi, Mozam- bique, Zambia and Zimbabwe. To see if observed trends were consistent with expected future changes we then compared these results with empirically downscaled rainfall projections for the mid-21st century from 7 general circulation models (GCMs, forced using the SRES A2 emissions scenario). This comparison was used to suggest where and when the 2 data sets were (in)consistent and highlighted some of the difficulties in using either observations or climate projections to suggest impacts (and implied adaptation options) in the future.

\section{DATA AND METHODS}

\subsection{Study region}

Fig. 1 presents the study region and the geographical distribution of the 104 stations used in the present study. The rainfall season is unimodal, with the start of the rains typically occurring during SeptemberOctober in the far north and south, whereas rains arrive later (November-December) in the central regions (Reason et al. 2005, Tadross et al. 2005a). Rainfed crop production normally occurs during DecemberFebruary, which is when rainfall variability and hence rain-fed crop production often varies with $\mathrm{ENSO}_{\text {; }}$ e.g. there is a strong relationship demonstrated between maize yields and ENSO in Zimbabwe (Cane et al. 1994). Whilst these relationships between total seasonal rainfall and maize yield are clear, it is often the intraseasonal character of rainfall (start of the rains, dry spells, etc.) that is important. For example, Phillips et al. (1998) demonstrated that earlier planting during ENSO years can avoid the mid-season dry spell or nitrogen-removing excessive rainfall when the maize crop is in its most vulnerable growth phase. The impact of rainfall variability on maize production is therefore clearly tied to the planting date and timing with respect to the crop phenological phases.

\subsection{Rainfall data}

Metadata for observed daily station rainfall data used in this analysis are given in Appendix 1. All the station data were quality controlled using Rclimdex software (http://cccma.seos.uvic.ca/ETCCDMI/index. shtml) which tested for negative precipitation and long periods of zero precipitation (see Peterson et al. 2002, New et al. 2006). Daily precipitation values $>450 \mathrm{~mm}$, whilst potentially real, are also potentially erroneous and were removed as a precaution. All negative rainfall values were removed. Missing data were often present, especially over Mozambique during periods 


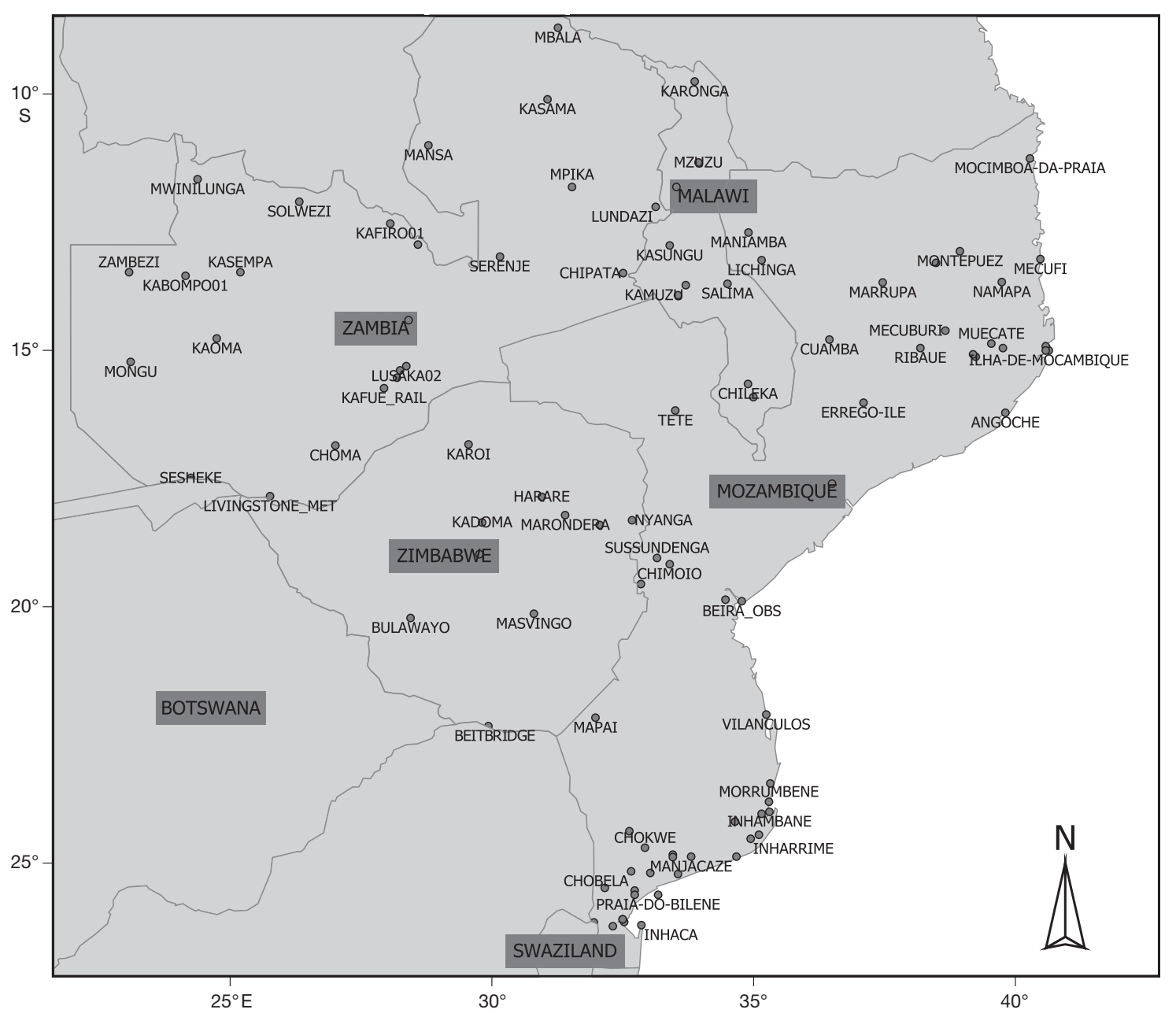

Fig. 1. Study area with meteorological stations

of civil strife, and an increase in missing data over time can lead to false trends. Therefore, to prevent missing data from introducing false trends in the derived indices: (1) planting and cessation indices were set to undefined if any missing data were encountered before they were defined; (2) all other indices were only calculated if planting and cessation dates were defined; and (3) all indices were set to undefined if any missing data were encountered in the calculation.

\subsection{Agricultural rainfall indices}

The following indices were designed to capture the most important aspects of rainfall affecting maize cropping. The first index is the start of rainfall sufficient for planting (which is assumed here to be the planting date). Together with the second index (cessation date), these indices can be used to measure the effective duration of the rainy season (third index). The first and third index can now be related to 2 important crop- specific farm management decisions facing a farmer planting rain-fed crops: when to plant and which seed or cultivar to plant. In the present study, the duration of the rainy season was directly related to the choice of maize cultivar; e.g. a $130 \mathrm{~d}$ maturing cultivar is appropriate for long rainy seasons, whereas a $90 \mathrm{~d}$ maturing cultivar is appropriate for shorter-duration seasons. Once a farmer has chosen the cultivar and decided when to plant, the success of the rain-fed maize crop is then dependent on climate characteristics during the following 90 to $130 \mathrm{~d}$.

In the present study we assumed a $130 \mathrm{~d}$ maturing crop with the following phenological cycle: Days 1 to 40 (germination phase), Days 41 to 110 (growth phase), and Days 111 to 130 (ripening phase). Rainfall characteristics that particularly impact maize growth during these phases are: (1) long dry spells during the germination and growth phases (limiting water availability), and (2) high intensity rainfall during the germination (resulting in water logging) and ripening (resulting in rotting and fungal infections) phases. 
Table 1. Naming convention for indices based on different planting dates

\begin{tabular}{|ll|}
\hline Suffix & Criteria used to define planting date \\
\hline A & $25 \mathrm{~mm}$ of accumulated rainfall in $10 \mathrm{~d}$ \\
B & $\begin{array}{l}25 \mathrm{~mm} \text { of accumulated rainfall in } 10 \mathrm{~d} \text {, without } 10 \\
\text { consecutive dry days (rainfall }<2 \mathrm{~mm} \text { ) occurring }\end{array}$ \\
in the next $20 \mathrm{~d}$ \\
C & $45 \mathrm{~mm}$ of accumulated rainfall in $4 \mathrm{~d}$ \\
\hline
\end{tabular}

The naming convention for the indices reflects 3 different definitions of planting date (Table 1). Indices ending with the suffix ' $A$ ' refer to a definition of planting based on minimal moisture required to sow and seeds to grow: $25 \mathrm{~mm}$ of cumulative rainfall in 10 consecutive days. The suffix ' $\mathrm{B}$ ' reflects a definition we adopted to account for a common problem associated with planting early: the risk of a long dry spell soon after planting. To address this, we defined a criterion for planting which is based on the earlier definition: 25 $\mathrm{mm}$ in $10 \mathrm{~d}$, without 10 consecutive dry days (rainfall $<2 \mathrm{~mm}$ ) occurring in the next $20 \mathrm{~d}$. If Planting_A and Planting_B are different, we consider the season has a false start. Indices ending with the suffix ' $\mathrm{C}$ ' are based on a definition of planting from Raes et al. (2004): $45 \mathrm{~mm}$ of cumulative rainfall in 4 consecutive days. All planting indices are set to the first day their respective criteria occur after 1 August (before the start of the rainy season).

A single definition of seasonal cessation -3 consecutive dekads (10 d periods) of $<20 \mathrm{~mm}$ each, occurring after 1 February (approximately the middle of the rainfall season) - together with the 3 planting criteria define 3 indices of rainy season duration: Duration_(A, $B, C)$. Within each of the 3 periods defined by planting and cessation days, we calculated the mean and maximum dry spell duration (number of consecutive dry days), the fraction of days with rain and total rainfall. All indices assume a dry day as one with $\leq 2 \mathrm{~mm} \mathrm{~d}^{-1}$ rainfall, and a wet day as one with $>2 \mathrm{~mm} \mathrm{~d}^{-1}$ rainfall; these indices are presented in Table 2.

Crop-specific indices assume a $130 \mathrm{~d}$ maturing maize varietal, based on the germination, growth and ripening phases described earlier. For each of these phases we calculated the total rainfall, rain day frequency and mean rainfall intensity on rainy days to understand the potential implications of changes in rainfall intensity and frequency.

\subsection{Long-term trends and correlations with large- scale climate anomalies}

Given that the anthropogenic signal in global temperature is only distinguishable from natural variability during the latter half of the 20th century (Stott et al. 2003), we determined trends for each station for data available from 1960 onwards. All indices in Table 2 were tested for trends using a robust regression, which is less sensitive to outliers (Press et al. 1993), with significance ( $90 \%$ probability that the trend is not zero) indicated using the non-parametric Mann-Kendall test. Several studies have suggested that there may be links between ENSO and/or the AAO and intraseasonal rainfall characteristics over parts of southern Africa (Usman \& Reason 2004, Reason et al. 2005, Tadross et al. 2005a). As a simple test of potential links with these

Table 2. Crop-specific indices based on maize phonological phases. All indices (besides Cessation) are calculated for each of the different criteria for the definition of planting (A, B, C: see Table 1). Dekad: 10 d period

\begin{tabular}{ll}
\hline Index & Definition \\
\hline Planting & Time of planting (d after 1 Aug). See Table 1 for definition of each planting criteria) \\
Cessation & Time of cessation: 3 consecutive dekads, each <20 mm (d after 1 Feb) \\
Duration & Duration of rainy season $(d)$ \\
DrySpellMax & Maximum dry spell duration within the season (d) \\
DrySpellMean & Mean dry spell duration within the season $(d)$ \\
RainDayFr & Fraction of rainy days within the season \\
TotRain & Total rainfall within the season (mm) \\
GermTotRain & Total rainfall during germination phase (from planting to planting $+40 \mathrm{~d})$ \\
GermRainDayFr & Fraction of rainy days during germination phase \\
GermRainInt & Mean rainfall intensity on a rainy day during germination phase \\
GrowTotRain & Total rainfall during growth phase (from planting $+40 \mathrm{~d}$ to planting $+110 \mathrm{~d})$ \\
GrowRainDayFr & Fraction of rainy days during growth phase \\
GrowRainInt & Mean rainfall intensity on a rainy day during growth phase \\
RipeTotRain & Total rainfall during ripening phase (from planting $+110 \mathrm{~d}$ to planting $+130 \mathrm{~d})$ \\
RipeRainDayFr & Fraction of rainy days during ripening phase \\
RipeRainInt & Mean rainfall intensity on a rainy day during ripening phase \\
\hline
\end{tabular}


large-scale climate anomalies, each index time series was correlated with the Southern Oscillation Index (SOI, www.cgd.ucar.edu/cas/catalog/climind/soi.html) and the AAO (http://jisao.washington.edu/data/aao/ \#data) during September, October and Novembermonths straddling the start of the rainfall season. Correlations were calculated using Kendall's tau, which is a rank-based measure of (assumed linear) association, recommended when variables are nonnormally distributed. As indices were potentially not defined for all years because of missing data, trends and correlations were only calculated when indices were available for $30 \mathrm{yr}$ or more. All defined trends were mapped to station locations and kriged onto a regular $0.5 \times 0.5^{\circ}$ grid (maximum distance of a station's influence set to $1^{\circ}$ ).

\subsection{Climate change projections}

Empirically downscaled climate change projections were calculated using the method of Hewitson \& Crane (2006) and applied to the control and future periods of the 7 GCMs presented in Table 3 (forced using the SRES A2 emissions scenario). This downscaling was trained on observed daily rainfall records from stations reporting on the General Telecommunications System (GTS) and is presented in Christensen et al. (2007). The GTS station data were not available for the same stations as used in the observational analysis but nevertheless provide reasonable coverage of the study region. During training, the downscaling derives a probability density function (PDF) of observed rainfall for each typical large-scale daily atmospheric circulation. For each day in the GCM time series it then samples from the PDF associated with the GCM atmospheric circulation on that day. Because the training is performed using observed (NCEP reanalysis) circulation fields, GCM biases are reflected in both the control and future simulations. We therefore present the future anomaly or change between the control and future climate.

\section{OBSERVED VARIABILITY AND TRENDS}

\subsection{Planting dates and duration of rainy season}

Mean planting dates (days after 1 August) for planting criteria B (Planting_B) are shown in Fig. 2a and occurred on average 80 to $140 \mathrm{~d}$ after 1 August. Dates for planting criteria A (data not shown) occurred on average 40 to $80 \mathrm{~d}$ after 1 August, indicating that the test for a false start to the season (Planting_B) shifts the mean planting date 40 to 60 d later and is an important consideration. Planting criteria C (data not shown) occurred 100 to $140 \mathrm{~d}$ after 1 August across much of the subregion and can therefore be considered the planting criterion that occurs, on average, the latest. Mean cessation dates (Fig. 2b) indicate that the rainfall season ends first in southern Mozambique, Zimbabwe and southern Zambia (200 to 240 d after 1 August), with northern tropical regions receiving consistent rain up to 2 mo later ( 240 to 280 d after 1 August).

Fig. 3 indicates robust trends (1960-2005) of Planting_B and Cessation $\left(\mathrm{d} \mathrm{yr}^{-1}\right)$. Planting_B (Fig. 3a) dates indicate significant trends for a later start to the season in the northern regions over Zambia and Malawi. Elsewhere trends are mostly not significant. Cessation dates (Fig. 3b) tend to arrive earlier over the northern regions and where trends are significant they are negative.

Fig. 4a indicates the mean seasonal duration for Duration_B, which generally reflects the pattern seen for seasonal cessation (Fig. 2b). The shortest mean seasonal duration (90 to 120 d) occurred towards the southwest, with longer seasons further north and east. Whilst 90 to $120 \mathrm{~d}$ is sufficient for growing short-season maize cultivars ( 90 d), it is borderline for a $130 \mathrm{~d}$ cultivar (which needs approximately $110 \mathrm{~d}$ if we ignore the $20 \mathrm{~d}$ ripening period at the end of the season). This southwestern region is, therefore, on average close to this critical threshold of seasonal duration and it is clear that farmers would want to plant as early as possible to minimise the risk of crop failure.

Fig. 4b indicates a decreasing trend (1960-2005) in Duration_B over northern regions (except northwest

Table 3. The 7 general circulation models GCMs used to downscale the projected climate of 2046-2065. CMIP3: Third Coupled Model Intercomparison Project. Further details are available at www.pcmdi.llnl.gov/ipcc/model_documentation/ipcc_model_ documentation.php

\begin{tabular}{|lll|}
\hline Originating group(s) & Country & CMIP3 ID \\
\hline Canadian Centre for Climate Modelling \& Analysis & Canada & CGCM3.1(T63) \\
Météo-France/Centre National de Recherches Météorologiques & France & CNRM-CM3 \\
CSIRO Atmospheric Research & Australia & CSIRO-Mk3.0 \\
Max Planck Institute for Meteorology & Germany & ECHAM5/MPI-OM \\
US Dept. of Commerce/NOAA/Geophysical Fluid Dynamics Laboratory & USA & GFDL-CM2.1 \\
NASA/Goddard Institute for Space Studies & USA & GISS-ER \\
Institut Pierre Simon Laplace & France & IPSL-CM4 \\
\hline
\end{tabular}




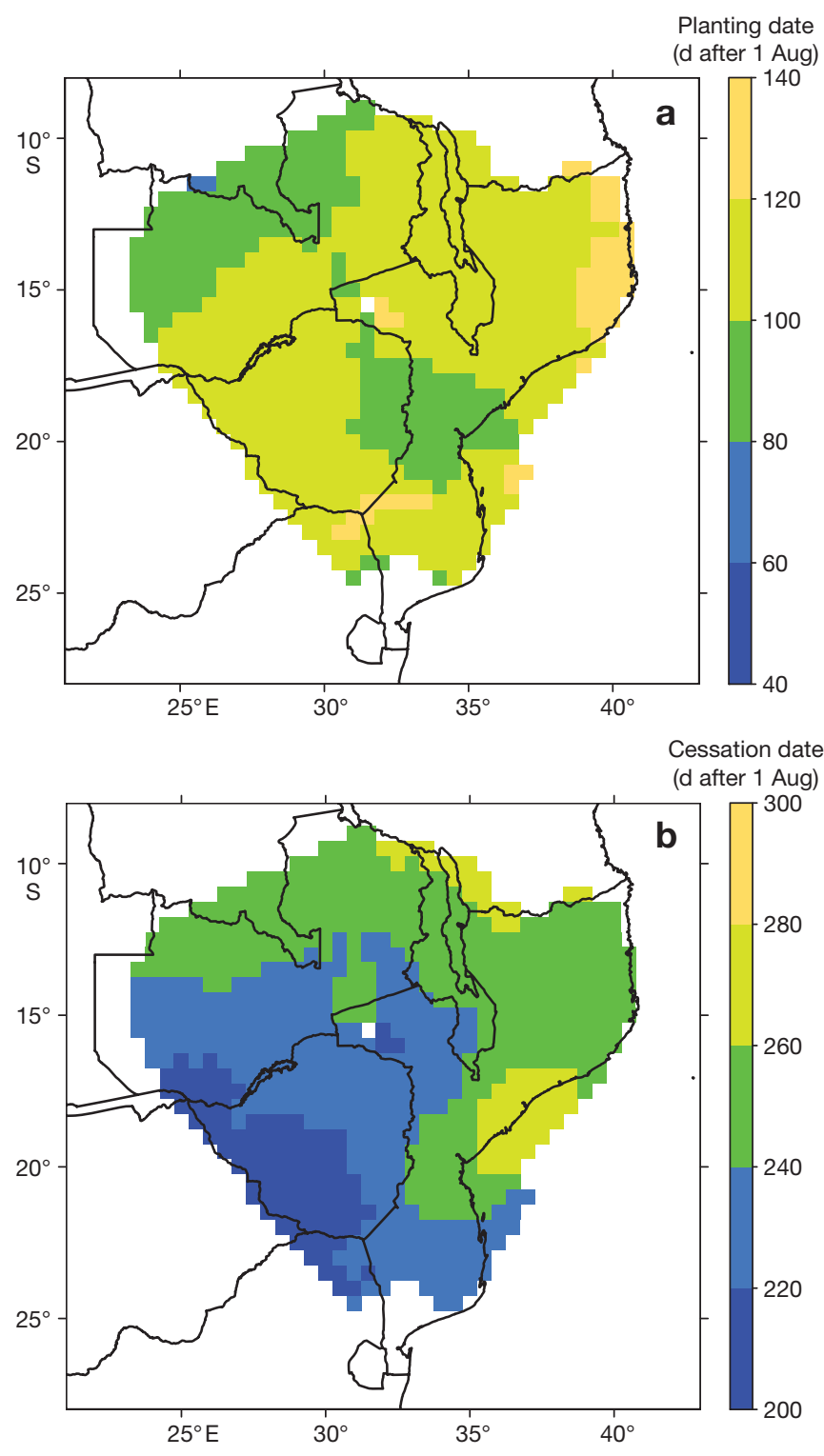

Fig. 2. Mean (a) planting and (b) cessation dates assuming planting when rainfall is (a) $25 \mathrm{~mm}$ in $10 \mathrm{~d}$ not followed by a dry spell of $10 \mathrm{~d}$ or longer (Planting_B), (b) rainfall cessation when 3 consecutive dekads of $<20 \mathrm{~mm}$ each occur

Zambia), extending through to southern Zambia and confirming the findings of Hachigonta et al. (2008). Whilst most stations indicate insignificant trends, over southern Zambia this negative trend coincides with the region close to the critical threshold of seasonal duration for growing maize (Fig. 4a). This is further demonstrated in Fig. 5, which shows the time series of Duration_B - the earliest realistic planting date (assuming Planting_A is associated with damaging dry spells). Whilst mostly remaining above the critical threshold between 1960 and 1980, Duration_B is more often than not below the critical $110 \mathrm{~d}$ threshold (red line) post-1980. A similar plot of Duration_C (data not

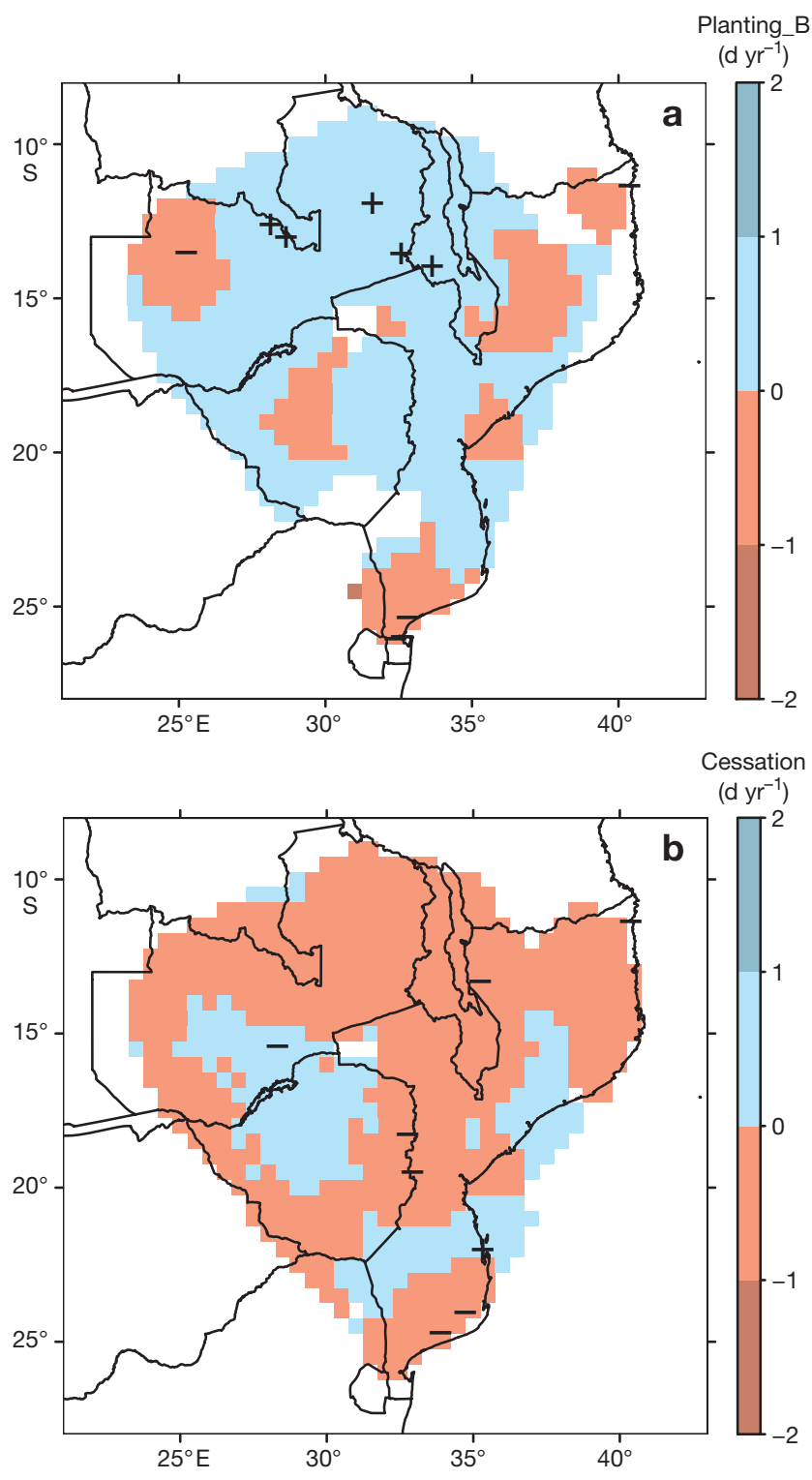

Fig. 3. Robust trends (1960-2005) of (a) Planting_B and (b) Cessation. Significant trends (at $90 \%$ CI) marked with +/-

shown) indicated that the later planting criteria rarely offered $>50 \%$ probability of sufficient seasonal duration for the $130 \mathrm{~d}$ cultivar and so is not a realistic planting criterion. Whilst Fig. 5 clearly demonstrates the importance of interannual variability, it is also clear from this example that if regions are close to critical thresholds, even non-significant trends in rainfall can have significant impacts on the risk of crop failure.

To further investigate interannual variability, all indices were correlated with SOI and AAO. Spatially extensive positive correlations were found between September SOI and Planting_A (Fig. 6a), though not with Planting_B (Fig. 6b), suggesting that El Niño (negative SOI) brings early rains, though with long dry 


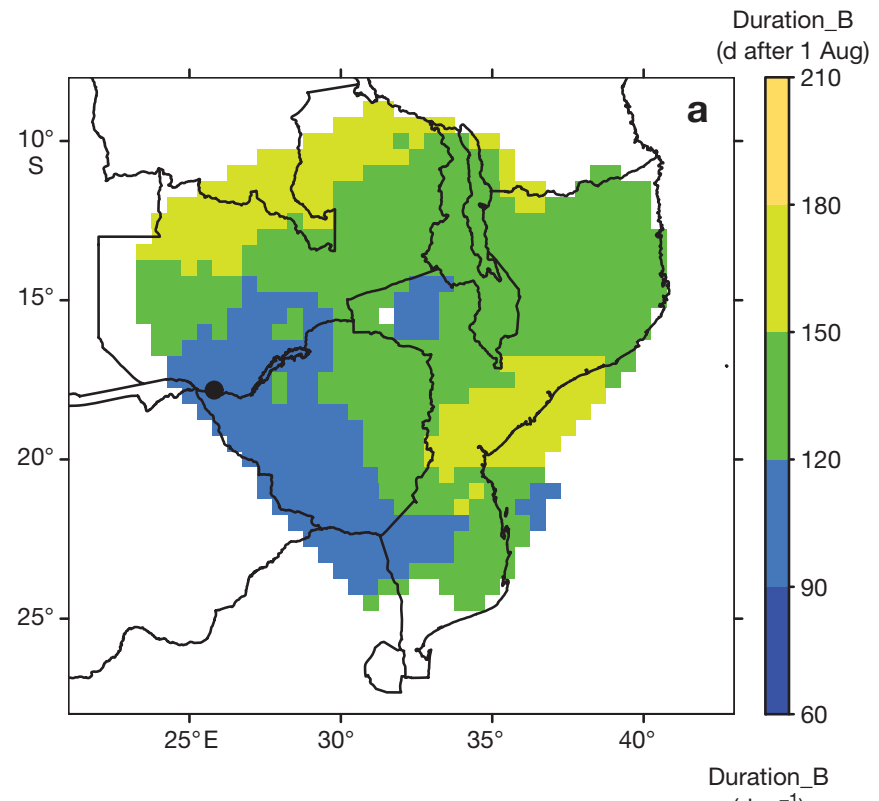

$\left(\mathrm{d} \mathrm{yr}^{-1}\right)$

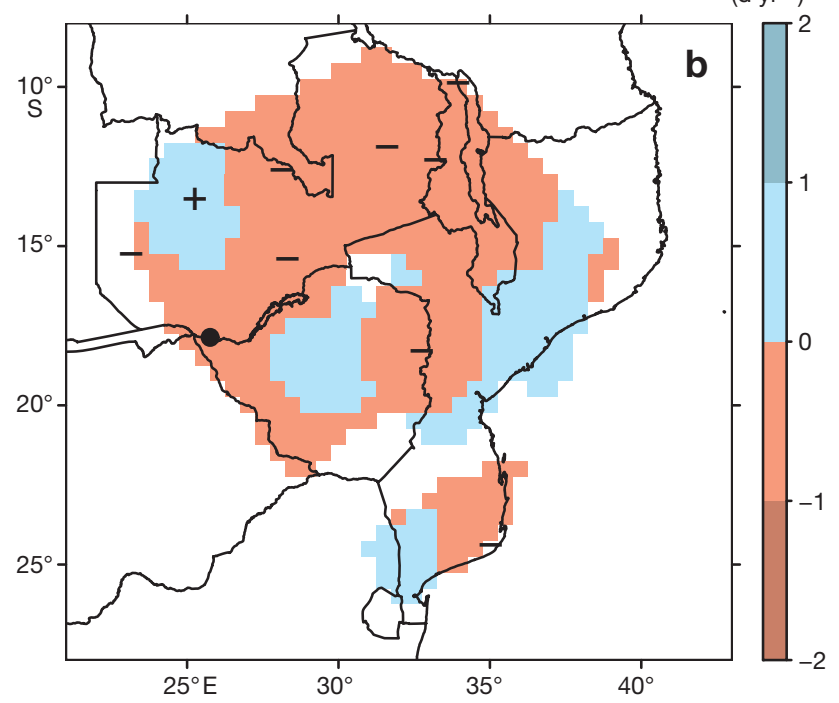

Fig. 4. (a) Mean Duration_B and (b) trends in Duration_B since 1960. Significant trends (at 90\% CI) marked with +/-. $(\bullet)$ : location of Livingstone

spells which prevent the Planting_B criteria from being satisfied. This is true mostly for the southern regions where El Niño is associated with a delayed start of consistent rainfall (Planting_B; Fig. 6b). Correlations between October SOI and Cessation (Fig. 6c) indicate that El Niño is also associated with an early Cessation, suggesting that La Nina events are associated with later Planting_A/Cessation and El Niño with an earlier Planting_A/Cessation (i.e. a shift in the seasonal boundaries). However, infrequent rainfall at the start of the season during an El Niño leads to a later start of consistent rainfall for Planting_B, which, when combined with earlier cessation, leads to a shorter season, as indicated by the positive correlations with seasonal

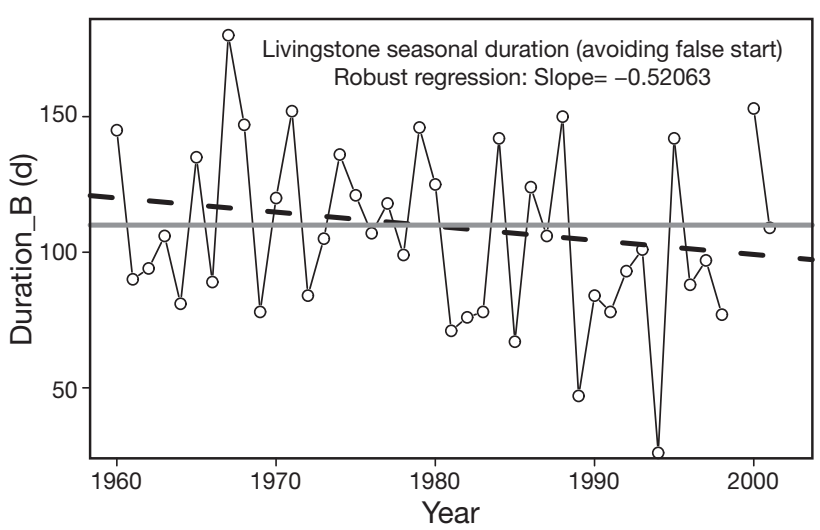

Fig. 5. Seasonal duration (Duration_B) at Livingstone, Zambia, 1960-2001. Dashed line: robust trend. Grey line: $110 \mathrm{~d}$ required for growing $130 \mathrm{~d}$ maize varietal

duration in Fig. 6d. Whilst further work is needed to elucidate the links between planting and/or cessation dates and ENSO, reliable predictions of either dates have potential benefits for water management: forecasts of planting dates can suggest whether a farmer should plant earlier or later than normal, whereas forecasts of cessation dates can help the farmer decide if they should store water to irrigate at the end of the season (should the rains end early).

\subsection{Within-season rainfall distribution}

Fig. 7a,b shows the correlations of September SOI with within-season (Planting_A to Cessation) mean dry spell duration (DrySpellMean_A) and rain day frequency (RainDayFr_A), respectively. Significant correlations across the region indicate that El Niño (La Niña) is associated with a reduced (increased) frequency of rain days and an increase (reduction) in mean dry spell length. Fig. $7 \mathrm{c}$, d presents the robust trends of DrySpellMean_A and RainDayFr_A, respectively, indicating that dry spell lengths have been increasing and the frequency of rain days decreasing over time, most significantly over Zambia, though extending into Zimbabwe and Malawi. This may be related to recent increases in the frequency of El Niño, though Fig. 5 would suggest other factors in the case of Livingstone, Zambia. Indeed, this shift to more sporadic rainfall is consistent with trends of an increasing frequency of high pressure anomalies found over the subcontinent, particulary the western parts, during the December-February 1979-2001 period (Hewitson et al. 2006). Those indices characterising intensity during the rainfall season indicated less spatially consistent and fewer significant changes, though this may change when using annual indices averaged over a wider region (New et al. 2006). It is therefore not surprising 

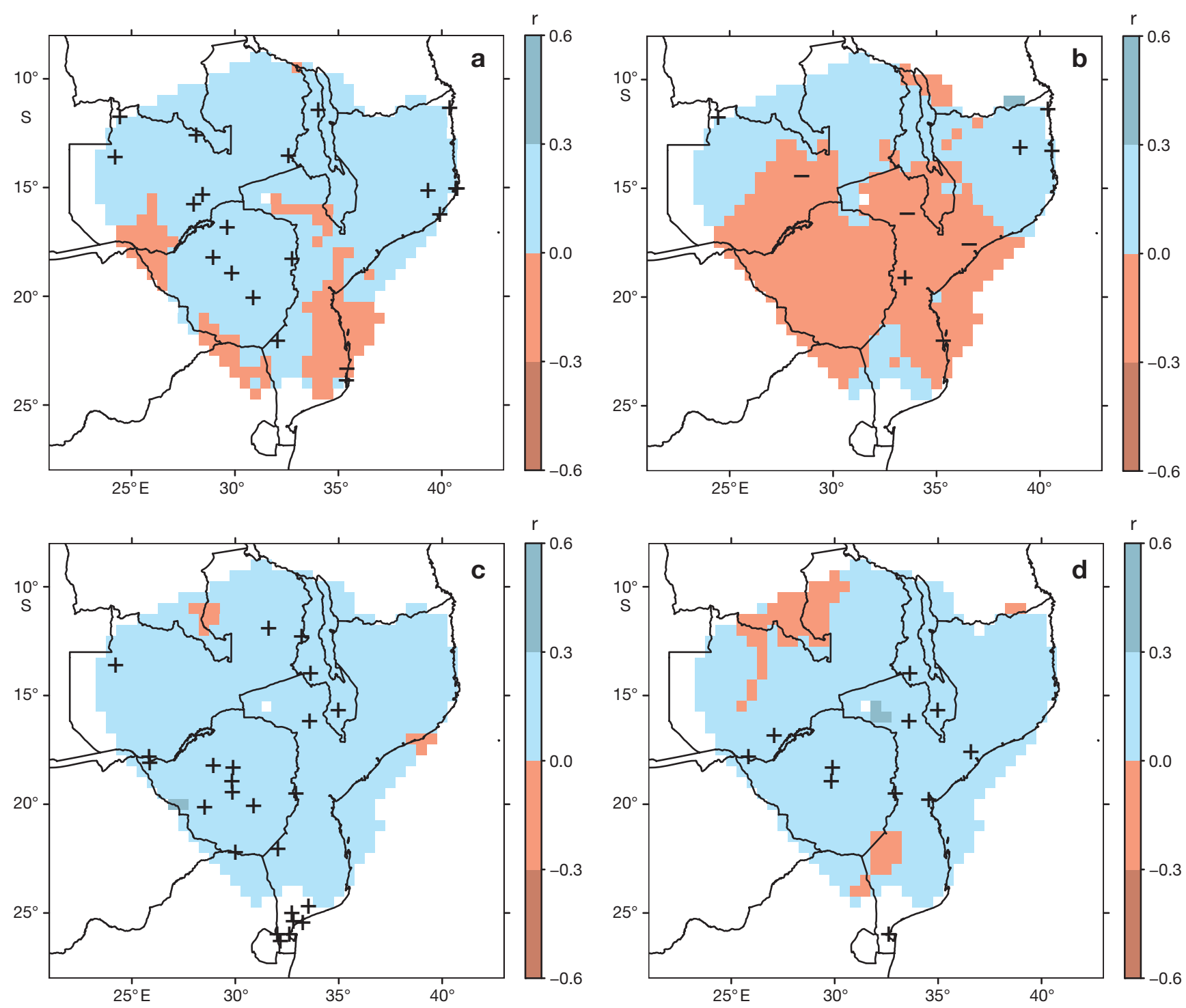

Fig. 6. Correlations between (a) September Southern Oscillation Index (SOI) and Planting_A, (b) September SOI and Planting_B, (c) October SOI and Cessation and (d) September SOI and Duration_B. Significant correlations (at 90\% CI) marked with +/-

that the dominant patterns of change in total rainfall indices reflect those seen for indices related to rain days (data not shown).

The association between El Niño and early, though erratic, rains is again clearly demonstrated in Fig. 8a, which shows the correlation of September SOI and the number of rain days during the first $40 \mathrm{~d}$ after Planting_A (GermRainDayFr_A). Positive correlations indicate that during El Niño the number of rain days is reduced. Indeed, correlations between SOI and most within-season rainfall indices related to rain days and total rainfall yielded extensive significant correlations (see Fig. 7b), whilst correlations between the AAO and indices reported so far remained mostly insignificant. However, correlations between November AAO and the number of rain days during the maize ripening phase (RipeRainDayFr_B, Fig. 8b) were significant over regions of Zimbabwe, southern Zambia and Malawi. The negative correlations suggest that when the AAO has a positive polarity (which it has tended towards over the last few decades, Marshall et al. 2004) and assuming Planting_B criteria, the number of rain days is reduced during the maize ripening phase. As dry conditions are often preferred to enhance the ripening process, this could be beneficial. However, a negative $\mathrm{AAO}$ and more rain days could negatively impact crop development, promoting pests and diseases in a mature maize crop. Given the relatively short duration of the ripening phase (20 d) and the trends noted for later planting times, the AAO could potentially become an important factor during the growth phase in the future. These results therefore imply that both SOI, 

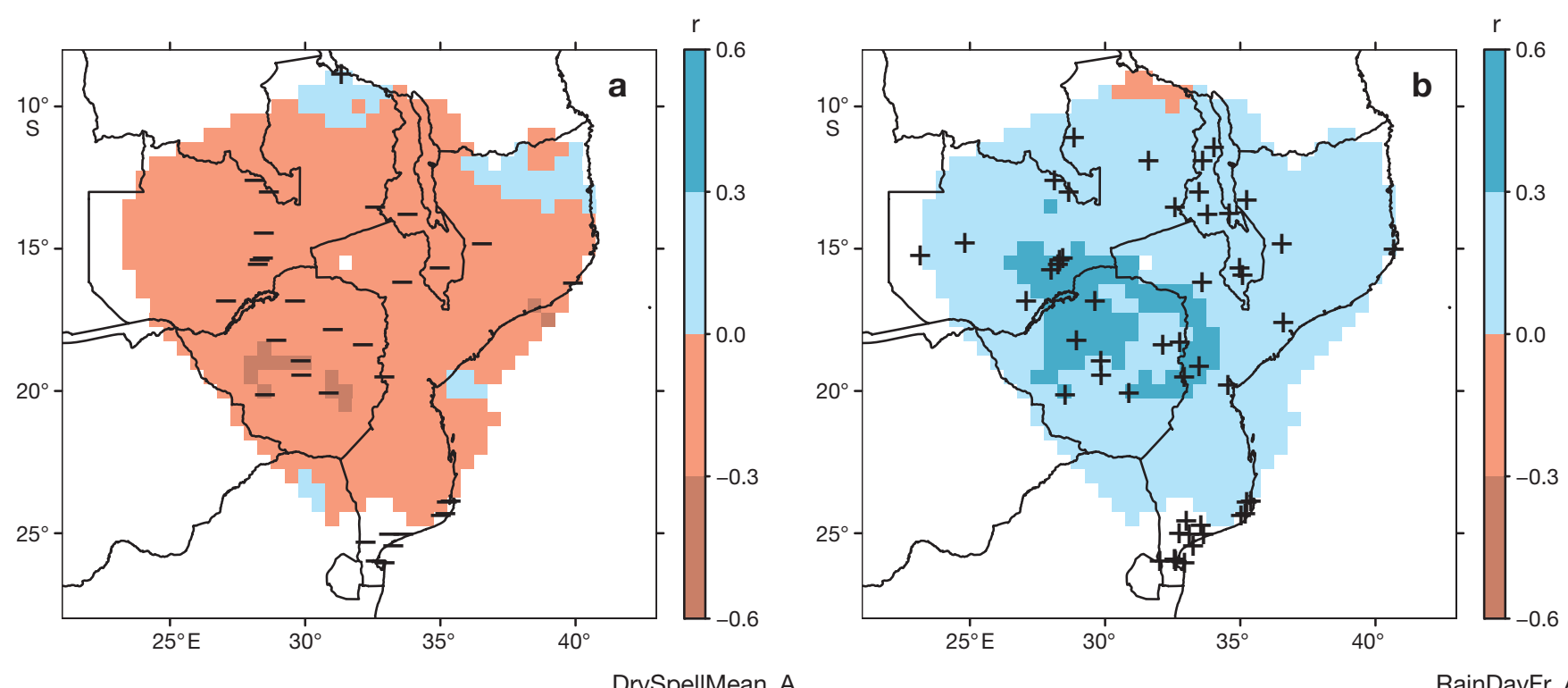

$\left(\mathrm{d} \mathrm{yr} \mathrm{r}^{-1}\right)$
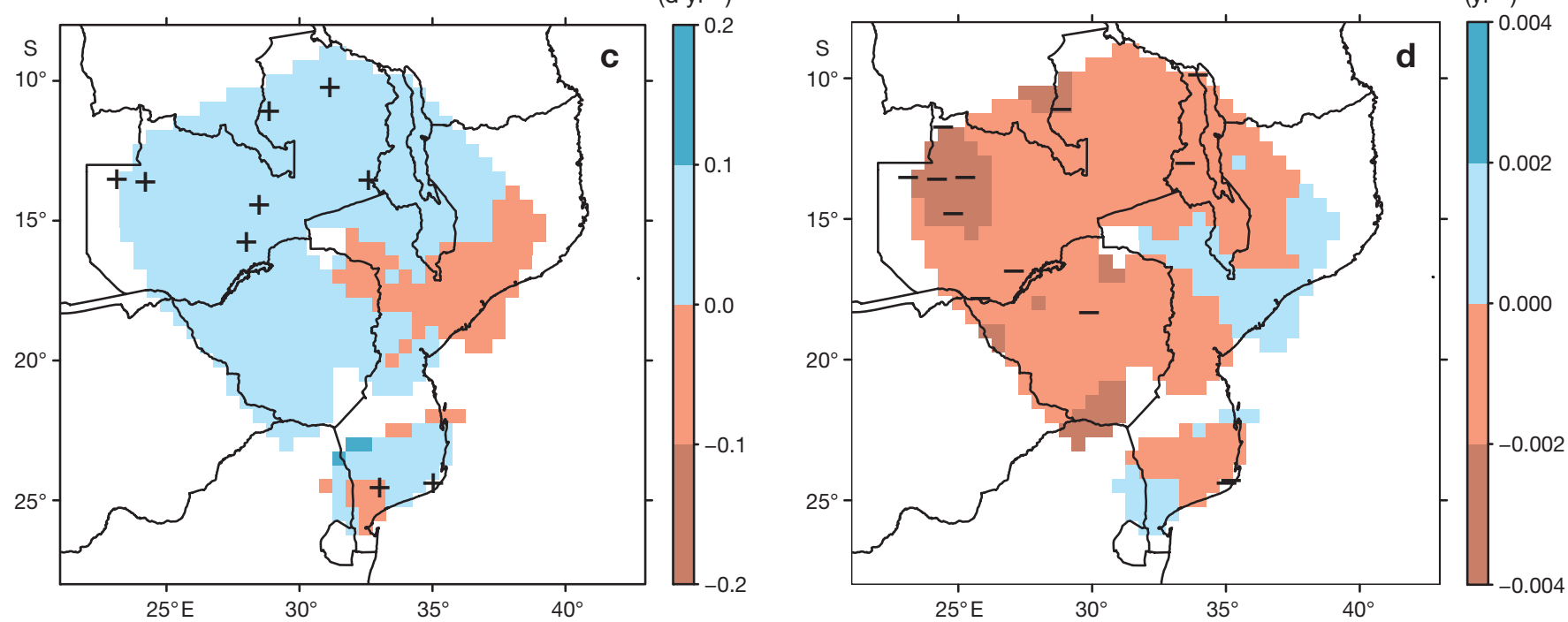

Fig. 7. Correlations of within-season (a) mean dry spell length (DrySpellMean_A) and (b) rain day frequency (RainDayFr_A) with September SOI. Trends in (c) DrySpellMean_A $\left(\mathrm{d} \mathrm{yr}^{-1}\right)$ and (d) RainDayFr_A $\left(\mathrm{yr}^{-1}\right)$ 1960-2005. Significant correlations/trends (at $90 \%$ CI) marked with +/-

through changes in the frequency of rain days during the season, and AAO, through changes in rain days towards the end of the season, can affect the amount of useful rainfall for growing maize.

\section{PROJECTED CHANGES UNDER ANTHRO- POGENIC CLIMATE CHANGE}

Noting the historical changes, we then compared them with rainfall projections for the mid-21st century (2046-2065) from the 7 GCMs detailed in Table 3. The locations of available empirically downscaled stations are shown in Fig. 9. Fig. 10 shows the median (of the 7
GCMs) expected change in total rainfall (average difference between the future [2046-2065] and control [1960-1990] periods of each GCM) for the September-November and March-May periods. Stations were spatially interpolated using a kriging function with a $1^{\circ}$ radius of influence. Increases of 0 to $10 \mathrm{~mm}$ were masked as they were less than expected increases in evapotranspiration due to increases in temperature (assuming increases in temperature of $2{ }^{\circ} \mathrm{C}$, potential evapotranspiration of $0.5 \mathrm{~mm} \mathrm{~d}^{-1}$ - using modified Thornthwaite [Pereira \& Pruitt 2004] and a crop coefficient of 0.2-representing bare ground; FAO 1998). Similar figures for the December-February and June-August seasons indicate less extensive changes 

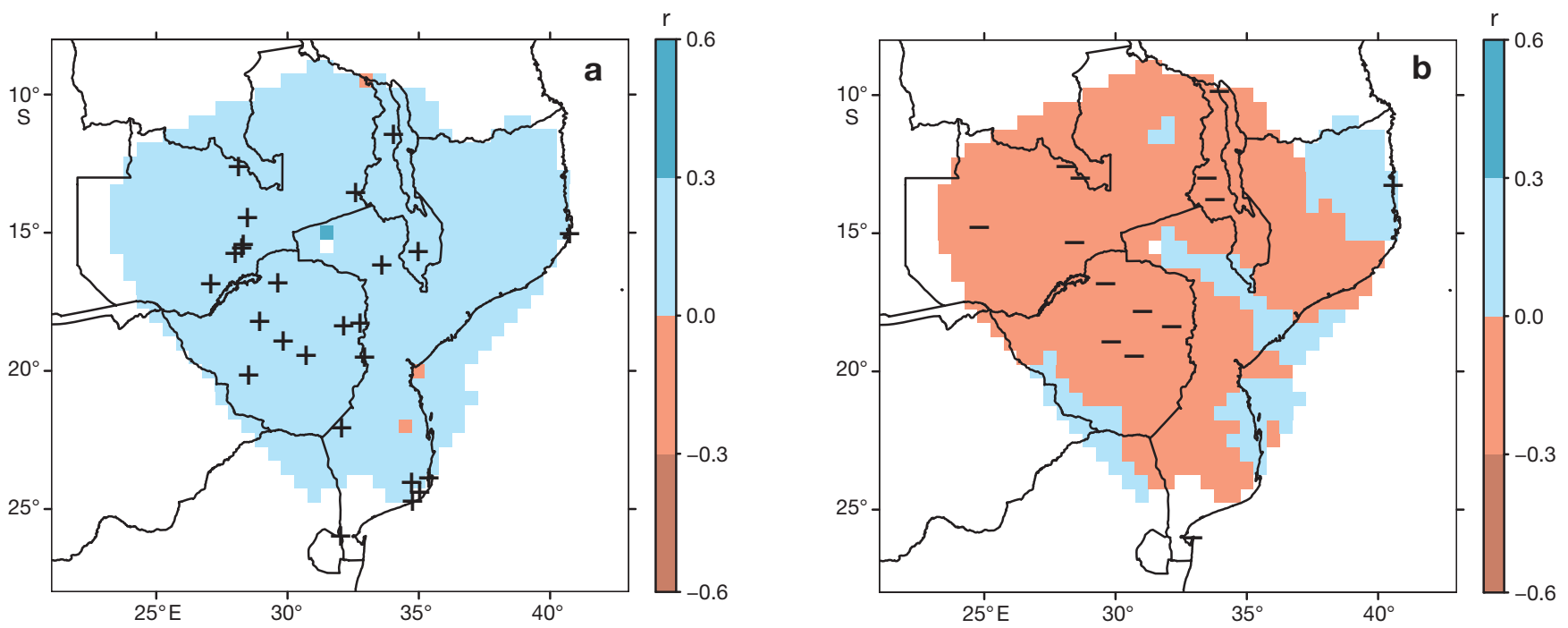

Fig. 8. Correlations between (a) September SOI and rainday frequency during the germination phase assuming Planting_A (GermRainDayFr_A) and (b) November AAO and rainday frequency during the ripening phase assuming Planting_B (RipeRain DayFr_B). Significant correlations (at $90 \%$ CI) marked with +/-

and are not shown. Fig. 10 demonstrates that spatially consistent changes are associated with a reduction in rainfall during early summer and an increase in late summer. Increases in late summer are generally further north and more extensive than decreases in early summer. These changes suggest that later planting dates may be expected, but later rainfall could extend the growing season.

To demonstrate differences between locations, Figs. $11 \& 12$ show the monthly changes in total rainfall, rain days $>2$ $\mathrm{mm}$, median daily rainfall intensity $(\mathrm{mm})$ and length of dry spells (days) at stations corresponding to Livingstone (Zambia) and Chitedze (Malawi). These stations were chosen for 2 reasons: the historical changes discussed earlier, and Chitedze station is the site of a micro-insurance project where rainfall changes may affect its long-term operations. The 2 stations, to some degree, also contrast changes expected in the west and further east. Fig. 11 demonstrates a median (thick horizontal line in boxplots) decrease in total rainfall during November and December at Livingstone (Stn 67843). This westward station is more likely to be influenced by projected increases in highpressure anomalies within the GCM forcing data (Hewitson et al. 2006), which will increase the likelihood of dry days; indeed the corresponding median projected changes in rain days are also negative (Fig. 11b). Clearly a wide range of changes are highlighted in the different GCMs (as indicated by the boxplot ranges) and for many months changes are not consistently predicted (in terms of whether a positive or negative change is consistently predicted). However, there are clear projected in-

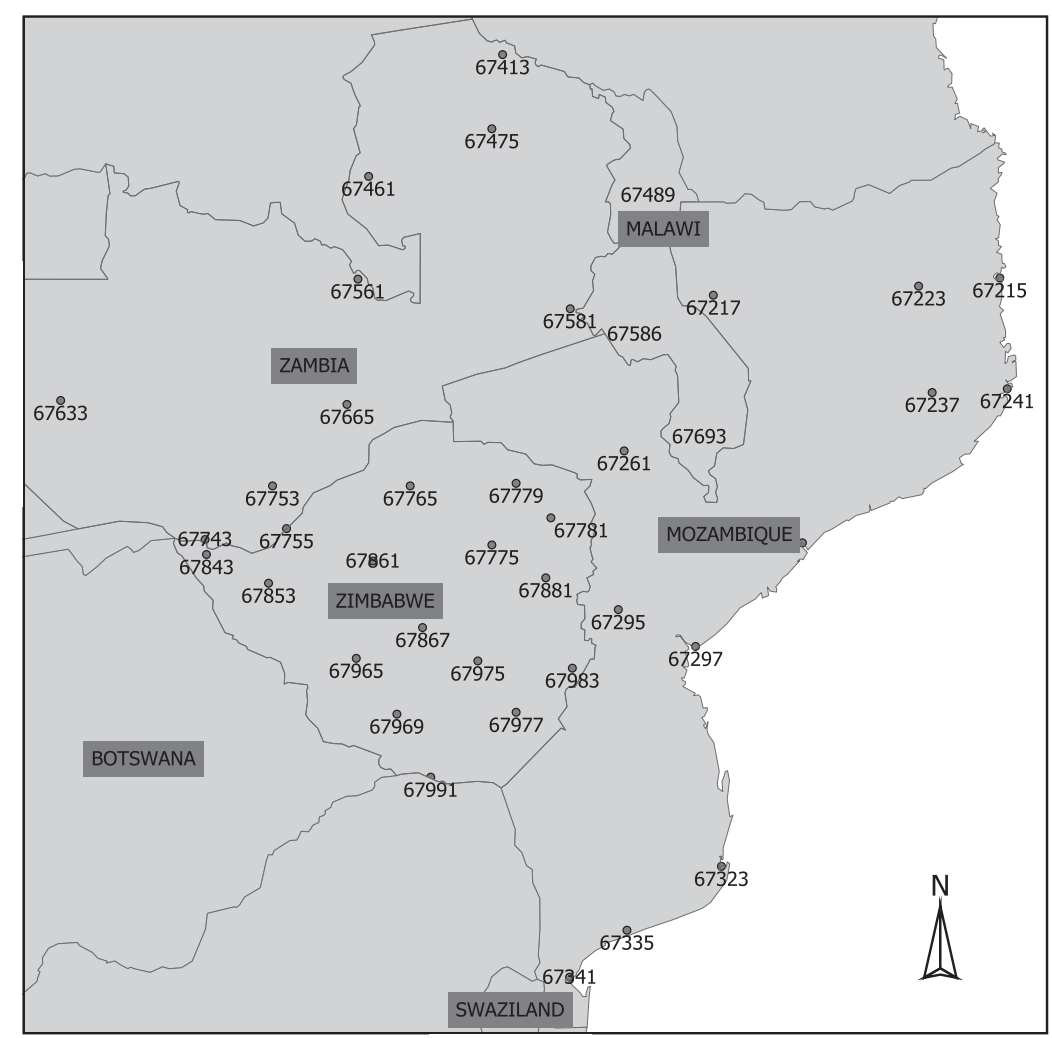

Fig. 9. World Meteorological Organization stations (including reference number) used to generate the empirically downscaled precipitation data 


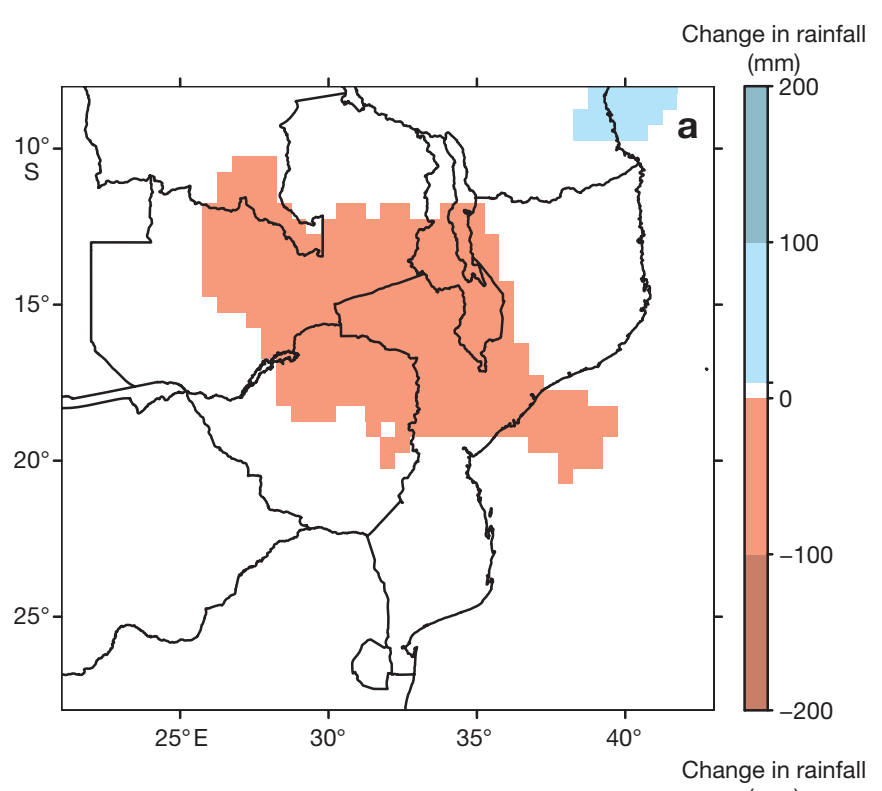
$(\mathrm{mm})$

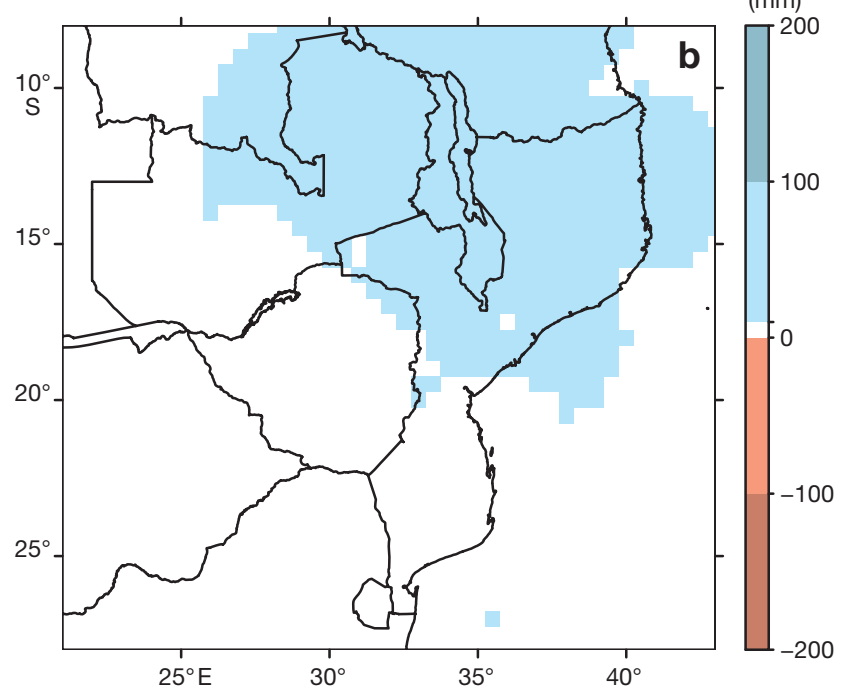

Fig. 10. Projected median change (future - control) in total rainfall for empirical downscaling of 7 general circulation models. (a) September-November, (b) March-May. Increases of $0-10 \mathrm{~mm}$ (less than increases in evapotranspiration) are masked out

creases in rainfall during the late summer, which are seen in total rainfall, number of rain days and median rain event (except during January and March when the increases in total rainfall are mostly due to increases in rain days). The length of dry spells decreases during most winter months (corresponding to the length of the dry season), indicating that increased rainfall at the end of the season mostly offsets decreases in rainfall during the following early summer period.

Fig. 12 demonstrates similar changes for Chitedze (67586), though with a tendency for more consistent
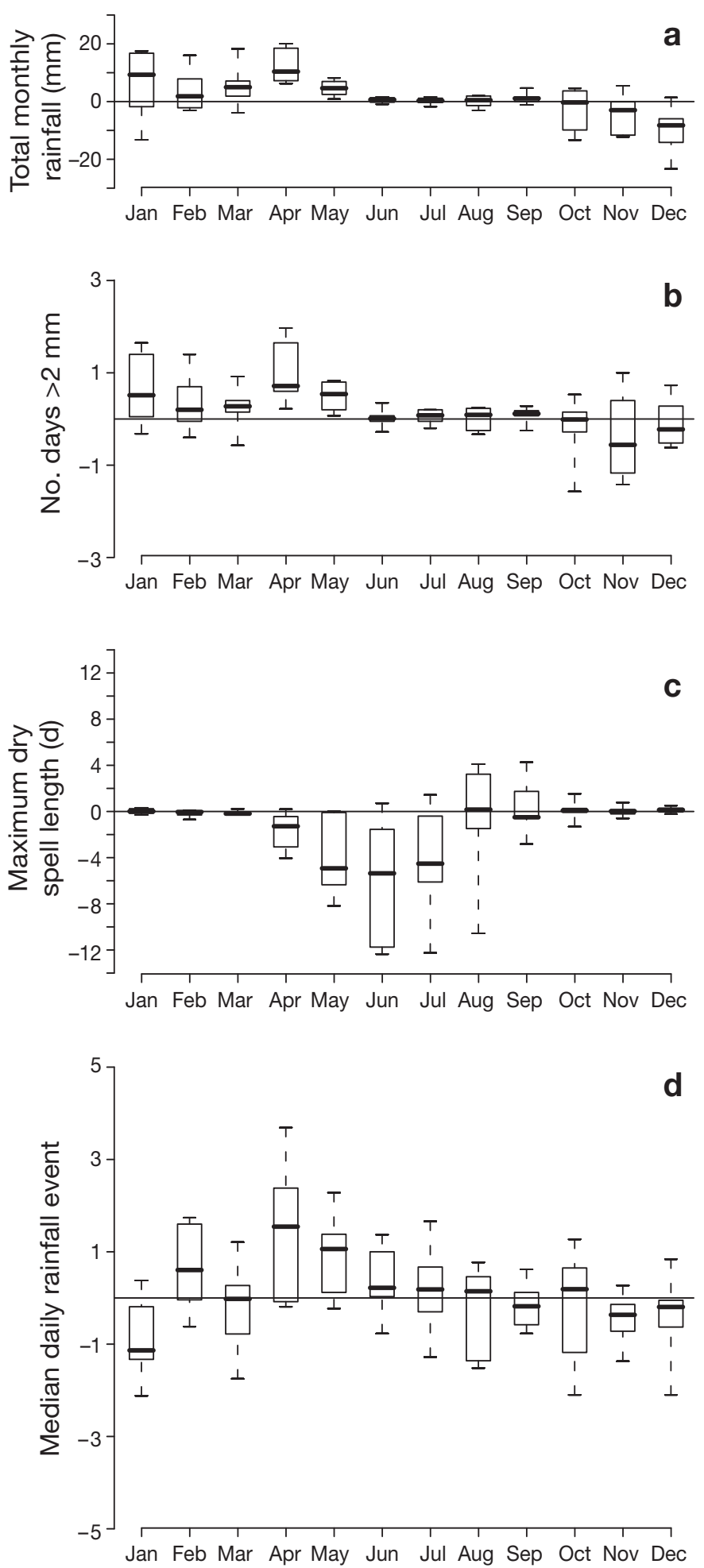

Fig. 11. Projected change (future - control) in rainfall at Livingstone station (Stn 67843) for empirical downscaling of 7 general circulation models (solid line represents the median, boxes the inter-quartile range and dashed lines the extreme model change). (a) Total monthly rainfall, (b) monthly number of rain days $>2 \mathrm{~mm}$, (c) maximum dry spell length, (d) median daily rainfall intensity $(\mathrm{mm})$ 

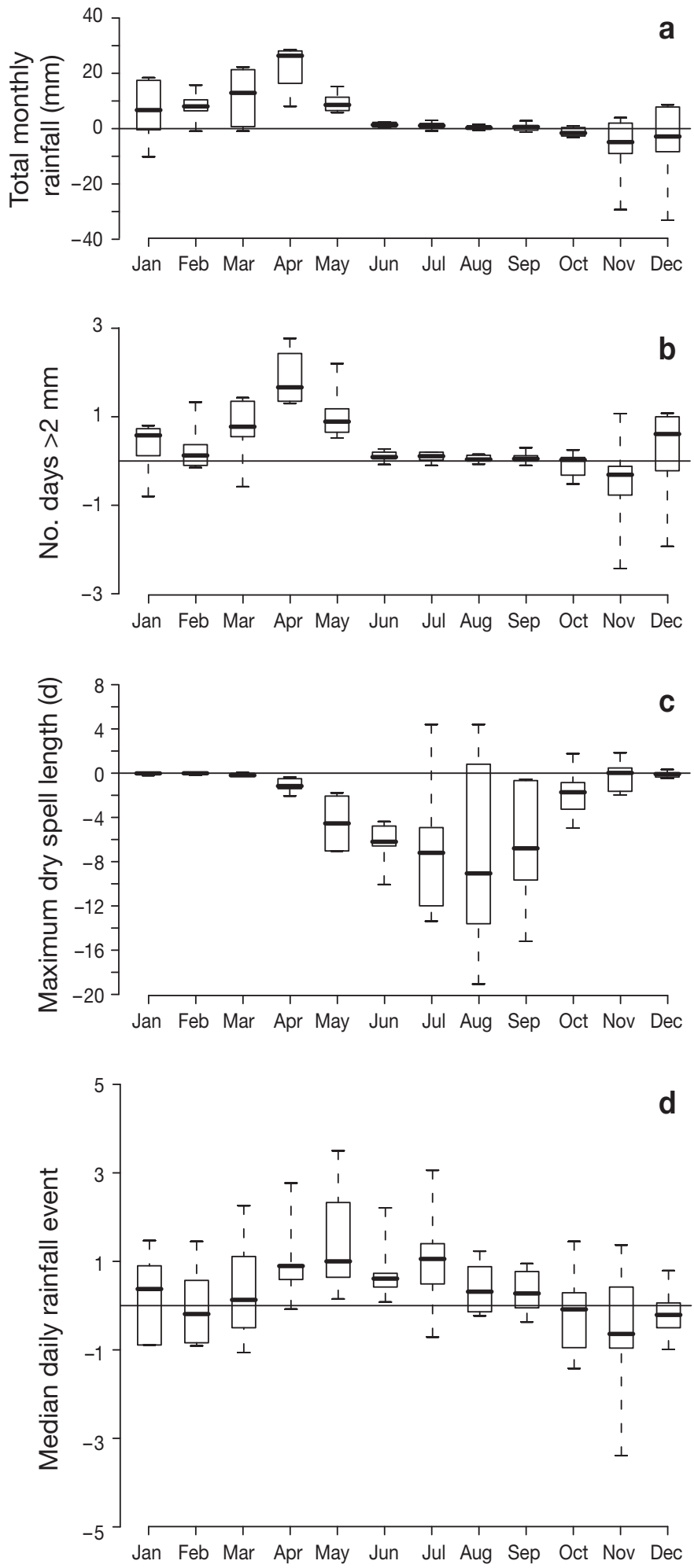

Fig. 12. Projected change (future - control) in rainfall at Chitedze station (Stn 67586) for empirical downscaling of 7 GCMs (solid line represents the median, boxes the inter-quartile range and dashed lines the extreme model change). (a) Total monthly rainfall, (b) monthly number of rain days $>2 \mathrm{~mm}$, (c) maximum dry spell length, (d) median daily rainfall intensity $(\mathrm{mm})$ increases in rainfall, starting earlier and of greater magnitude. These changes highlight those illustrated in Fig. 10, suggesting increases in late summer rainfall of greater magnitude towards the north, and decreases during early summer more towards the west. It also suggests that the timing of the greatest increases in rainfall during summer tends to come earlier for stations located further east. Together these projected changes suggest a later onset of consistent rainfall.

Whilst it is not possible to directly connect these results with the observed changes presented earlier, they are reasonably consistent with the observed trends for later planting dates, but are inconsistent with trends noted for rainfall cessation dates. It seems reasonable to suggest that the physical processes responsible for changes at the beginning and end of the rainfall season will be different. Therefore, the correspondence between observed and projected changes will always depend on the time of year and when in the future the responsible physical change will occur. This and the observed changes noted in Section 3 suggests that there may be periods when rainfall conditions are worse for maize cropping than at present, even though rainfall conditions may improve by 2046-2065 if later planting dates occur before cessation dates start to increase.

\section{SUMMARY}

Indices related to aspects of intraseasonal rainfall and maize cropping over southeastern Africa were calculated from daily observations of 104 stations across the region. Weak trends were noted for later planting and earlier cessation dates in the north, leading to shorter rainfall seasons. Over southern Zambia this brings the duration of the rainfall season closer to critical thresholds, which forces farmers to plant as early possible; trends at Livingstone station show that although insignificant, they lead to a greater risk that critical thresholds of seasonal duration required for maize cultivation are not met.

Climate variability, through both the AAO and ENSO (SOI), is also demonstrated to be an important additional pressure, altering the character of the cropping season in fundamental ways. Over much of the region, a negative SOI (El Niño) is associated with an early start to the season, though not necessarily with consistent rain, resulting from an increase in the number of dry days and mean dry spell length. An early cessation is also suggested, which places added strain on farmers who are faced with a shorter season of less consistent rain, with the temptation to plant early. Under these circumstances it is easy to see how crop failure is a regular occurrence during El Niño. Trends 
for later planting dates make it increasingly more difficult to grow maize; the window of useful rainfall for maize cropping appears to be shrinking in the north where climate variability may then impact cropping more frequently. Another important factor when planting late, and the cropping season extends into late summer/early autumn, is the mode of the AAO. If it promotes more rainfall during the ripening phase, this may have negative consequences for crop development (increased pests and diseases), though the phase of the AAO has, since the 1970s, been tending towards conditions that reduce rainfall. Whilst this is currently beneficial during the ripening phase, continued trends for later planting may eventually increase the influence of AAO during the growth phase, which will have a negative impact on crop yield.

Increases in mean dry spell length and reductions in rain day frequency were also demonstrated over Zambia, Malawi and Zimbabwe during the rainfall season. This is true particularly when the planting date is taken at its earliest (ignoring false starts), which suggests that changes are occurring at the beginning of the season, reinforcing evidence that the start of consistent rainfall for planting has been getting later over these regions. This is consistent with regional trends for later onset, an increase in the frequency of high pressures over the continent and increased length of the dry season (e.g. Tadross et al. 2005a; New et al. 2006).

Empirically downscaled climate change scenarios suggest that increases in late summer rainfall (total, number of rain days and median rainfall events) can be expected over widespread areas, especially towards the north and east. Changes in early summer are relatively more uncertain and again depend on location; further west these changes tend to be mostly negative.

Allowing for uncertainty in changes simulated under $\mathrm{CO}_{2}$-induced anthropogenic climate change, projected changes are not at odds with those changes noted in the observational record, though statements of attribution are not possible. Indeed, rainfall changes under climate change may not be distinguishable from natural variability for 70 or more years (Christensen et al. 2007). However, observed changes are significant and important, especially to those involved in agriculture. Furthermore, it should be noted that there have been documented increases in temperature (which are expected to continue to increase in the future), which places additional water-related stresses on agriculture even without changes in rainfall. Land-use changes and multidecadal climate factors can all have a bearing on observed trends, and even $\mathrm{CO}_{2}$-induced climate change may be nonlinear; reductions in rain days may be counteracted by increases in rainfall intensity and it is the relative strength of competing processes, at dif- ferent time scales moving into the future, that will determine changes found in the observational record. Understanding which of these changes occur together at different locations is a key requirement for formulating successful adaptation strategies and enhancing food security in the region.

Acknowledgements. We are grateful to the Bank Netherlands Partnership Program for providing funding through the Development Economics group of the World Bank. This work could not have been completed without the excellent and timely support of the National Meteorological Services of Malawi, Mozambique, Zimbabwe and Zambia. In particular, we thank G. Munthali, A. Chavula, A. Manhique and J. Kanyanga. We are also grateful to X. Zhang and F. Yang of Environment Canada for maintaining the Rclimdex code, part of which was used in developing the statistical analysis.

\section{LITERATURE CITED}

Ati FO, Stitger CJ, Oladipo EO (2002) A comparison of methods to determine the onset of the growing season in northern Nigeria. Int J Climatol 22:731-742

Buckland R, Eele G, Mugwara R (2000) Humanitarian crises and natural disasters: a SADC perspective. In: Clay E, Stokke O (eds) Food and human security. Frank Cass Publishers, London, p 181-195

Cane MA, Eshel G, Buckland RW (1994) Forecasting Zimbabwean maize yield using eastern equatorial Pacific seasurface temperature. Nature 370:204-205

Christensen JH, Hewitson B, Busuioc A, Chen A and others (2007) Regional climate projections. In: Solomon S, Qin D, Manning $\mathrm{M}$, Chen $\mathrm{Z}$ and others (eds) Climate change 2007: the physical science basis. Contribution of Working Group I to the Fourth Assessment Report of the Intergovernmental Panel on Climate Change. Cambridge University Press, Cambridge, p 847-940

> Dennett MD (1987) Variation of rainfall: the background to soil and water management in dryland regions. Soil Use Manag 3:47-57

FAO (1998) Crop evapotranspiration: guidelines for computing crop water requirements. FAO Irrigation and Drainage Paper 56. Food and Agriculture Organisation of the United Nations, Rome

FAO (2004) Drought impact mitigation and prevention in the Limpopo River Basin: a situation analysis. Land and water Discussion Paper 4. Food and Agricultural Organisation of the United Nations, Rome

Hachigonta S, Reason CJC, Tadross M (2008) An analysis of onset date and rainy season duration over Zambia. Theor Appl Climatol 91:229-243

> Hewitson BC, Crane RG (2006) Consensus between GCM climate change projections with empirical downscaling: precipitation downscaling over South Africa. Int J Climatol 26:1315-1337

Hewitson BC, Tadross MA, Afiesiemama E, Jain S and others (2006) The development of regional climate change scenarios for sub-saharan Africa. Assessment of impacts and adaptation to climate change project AF07. Available at www.aiaccproject.org/Final\%20Reports/Final\%20Reports/ FinalRept_AIACC_AF07.pdf. START secretariat, Washington, DC

Hulme M, Doherty R, Ngara T, New M, Lister D (2001) African climate change: 1900-2100. Clim Res 17:145-168 
Jones RG, Noguer M, Hassell DC, Hudson D, Wilson SS, Jenkins GJ, Mitchell JFB (2004) Generating high resolution climate change scenarios using PRECIS. Met Office, Hadley Centre, Exeter

Kurukulasuriya P, Mendelsohn R, Hassan R, Benhin J and others (2006) Will African agriculture survive climate change? World Bank Econ Rev 20:367-388

Lindesay JA (1988) South African rainfall, the Southern Oscillation and a Southern Hemisphere semiannual cycle. J Climatol 8:17-30

Marshall GJ, Stott PA, Turner J, Connolley WM, King JC, Lachlan-Cope TA (2004) Causes of exceptional atmospheric circulation changes in the Southern Hemisphere. Geophys Res Lett 31:L14205 doi: 10.1029/2004GL019952

Mason SJ (1995) Sea surface temperature: South African rainfall associations, 1910-1989. Int J Climatol 15:119-135

- New M, Hewitson BC, Stephenson DB, Tsiga A and others (2006) Evidence of trends in daily climate extremes over southern and west Africa. J Geophys Res 111:D14102 doi: 10.1029/2005JD006289

Pereira AR, Pruitt WO (2004) Adaptation of the Thornthwaite scheme for estimating daily reference evapotranspiration. Agric Water Manage 66:251-257

Peterson TC, Taylor MA, Demeritte R, Duncombe DL and others (2002) Recent changes in climate extremes in the Caribbean region. J Geophys Res 107:4601 doi: 10.1029/ 2002JD002251

Phillips J, Cane MA, Rosenzweig C (1998) ENSO, seasonal rainfall patterns and maize yield variability in Zimbabwe. Agric For Meteorol 90:39-50

Press WH, Flannery BP, Teukolsky SA, Vetterling WT (1993) Numerical recipes in C: the art of scientific computing. Cambridge University Press, Cambridge

Submitted: July 23, 2008; Accepted: June 9, 2009
Raes D, Sithole A, Makarau A, Milford J (2004) Evaluation of first planting dates recommended by criteria currently used in Zimbabwe. Agric For Meteorol 125:177-185

> Reason CJC, Rouault M (2005) Links between the Antarctic Oscillation and winter rainfall over western South Africa. Geophys Res Lett 32:L07705 doi: 10.1029/2005GL022419

Reason CJC, Hachigonta S, Phaladi RF (2005) Interannual variability of rainy season characteristics over the Limpopo region of southern Africa. Int J Climatol 25:1835-1853

Richard Y, Trzaska S, Roucou P, Rouault M (2000) Modification of the southern African rainfall variability/ENSO relationship since the late 1960s. Clim Dyn 16:883-895

Smale M, Jayne TS (2003) Maize in Eastern and Southern Africa: 'seeds' of success in retrospect. EPTD Discussion Paper No. 97, Environment and Production Technology Division, International Food Policy Research Institute, Washington, DC

Stott PA, Jones GS, Mitchell JFB (2003) Do models underestimate the solar contribution to recent climate change? J Clim 16:4079-4093

Tadross MA, Hewitson BC, Usman MT (2005a) The interannual variability of the onset of the maize growing season over South Africa and Zimbabwe. J Clim 18: 3356-3372

Tadross MA, Jack C, Hewitson BC (2005b) On RCM-based projections of change in southern African summer climate. Geophys Res Lett 32:L23713 doi: 10.1029/2005GL024460

Usman MT, Reason CJC (2004) Dry spell frequencies and their variability over southern Africa. Clim Res 26:199-211

> Usman MT, Archer E, Johnston P, Tadross M (2005) A conceptual framework for enhancing the utility of rainfall hazard forecasts for agriculture in marginal environments. Nat Hazards 34:111-129

Proofs received from author(s): August 27, 2009 
Appendix 1. Station name, country, location and available period of daily rainfall data

\begin{tabular}{|c|c|c|c|c|c|c|c|c|c|}
\hline Station name & $\begin{array}{l}\text { Latitude } \\
\quad\left({ }^{\circ} \mathrm{S}\right)\end{array}$ & $\begin{array}{l}\text { Longitude } \\
\left({ }^{\circ} \mathrm{E}\right)\end{array}$ & $\begin{array}{l}\text { Altitude } \\
(\mathrm{m})\end{array}$ & Period & Station name & $\begin{array}{c}\text { Latitude } \\
\left({ }^{\circ} \mathrm{S}\right)\end{array}$ & $\begin{array}{l}\text { Longitude } \\
\left({ }^{\circ} \mathrm{E}\right)\end{array}$ & $\begin{array}{l}\text { Altitude } \\
(\mathrm{m})\end{array}$ & Period \\
\hline Malawi & & & & & Massinga & 23.32 & 35.4 & 109 & 1951-2004 \\
\hline Karonga & 9.88 & 33.95 & 529 & 1961-2005 & Inhamussua & 23.9 & 35.23 & 37 & $1951-1996$ \\
\hline Mzuzu & 11.43 & 34.02 & 1254 & $1961-2005$ & Chimoio & 19.12 & 33.47 & 731 & $1951-2003$ \\
\hline Mzimba & 11.9 & 33.6 & 1349 & $1933-2005$ & Messambuzi & 19.5 & 32.92 & 966 & $1951-1999$ \\
\hline Kasungu & 13.02 & 33.47 & 1058 & $1961-2005$ & Sussundenga & 19 & 33.23 & 620 & $1969-1999$ \\
\hline Salima & 13.75 & 34.58 & 512 & $1954-2005$ & Maputo_Observatori & io25.97 & 32.6 & 60 & $1927-2004$ \\
\hline Kamuzu & 13.78 & 33.78 & 1229 & $1961-2005$ & Namaacha & 25.98 & 32.02 & 523 & $1911-1990$ \\
\hline Chitedze & 13.97 & 33.63 & 1149 & $1961-2005$ & Umbeluzi_Agricola & 26.05 & 32.38 & 12 & $1924-2005$ \\
\hline Chileka & 15.67 & 34.97 & 767 & $1949-2005$ & Manhica & 25.37 & 32.8 & 35 & $1951-2000$ \\
\hline Bvumbwe & 15.92 & 35.07 & 1146 & $1961-2005$ & Inhaca & 26.03 & 32.93 & 27 & $1954-2000$ \\
\hline Zambia & & & & & Chobela & 25 & 32.73 & 15 & $1941-2000$ \\
\hline Chipata & 13.55 & 32.58 & 1140 & 1945-2002 & Maputo_Mavalane & 25.92 & 32.57 & 39 & $1956-2004$ \\
\hline Choma & 16.85 & 27.07 & 1200 & $1951-2002$ & Changalane & 26.3 & 32.18 & 100 & $1962-2004$ \\
\hline Kabompo & 13.6 & 24.2 & 1100 & $1961-2002$ & Benfica & 25.92 & 32.57 & 37 & $1970-2000$ \\
\hline Kabwe & 14.45 & 28.47 & 1140 & $1951-2002$ & Sabie & 25.32 & 32.23 & 80 & $1951-1991$ \\
\hline Kafiro & 12.6 & 28.12 & 1243 & $1967-2002$ & Ilha_de_Mocambique & e 15.03 & 40.73 & 9 & $1955-1991$ \\
\hline Kafue & 15.75 & 28 & 1140 & $1957-2002$ & Namapa & 13.72 & 39.83 & 200 & $1961-1998$ \\
\hline Kaoma & 14.8 & 24.8 & 1120 & $1961-2002$ & Ribaue_Agricola & 14.98 & 38.27 & 535 & $1955-1999$ \\
\hline Kasama & 10.22 & 31.13 & 1300 & $1933-2002$ & Angoche & 16.22 & 39.9 & 61 & $1951-2001$ \\
\hline Kasempa & 13.53 & 25.25 & 1160 & $1938-2002$ & Meconta & 14.98 & 39.85 & 235 & $1951-1997$ \\
\hline Livingstone & 17.82 & 25.82 & 960 & $1932-2002$ & Nampula_Agricola & 15.15 & 39.33 & 432 & 1951-1998 \\
\hline Lundazi & 12.28 & 33.2 & 1280 & $1956-2002$ & Muecate & 14.9 & 39.63 & 280 & $1951-2001$ \\
\hline Lusaka02 & 15.33 & 28.43 & 1200 & $1967-2002$ & Mossuril & 14.95 & 40.67 & 15 & $1951-1999$ \\
\hline Lusaka01 & 15.41 & 28.31 & 1252 & $1950-2002$ & Mecuburi & 14.65 & 38.75 & 468 & $1951-2000$ \\
\hline Mansa & 11.1 & 28.85 & 1140 & $1960-1998$ & Lumbo & 15.03 & 40.67 & 10 & $1956-2001$ \\
\hline Mbala & 8.85 & 31.33 & 1660 & $1961-2002$ & Nampula & 15.1 & 39.28 & 438 & $1956-2003$ \\
\hline Mongu & 15.25 & 23.15 & 1060 & $1935-2002$ & Maniamba & 12.77 & 34.98 & 1 & $1951-2000$ \\
\hline Mt_Makulu & 15.55 & 28.25 & 1160 & $1961-2002$ & Cuamba & 14.82 & 36.53 & 606 & $1951-2001$ \\
\hline Mpika & 11.9 & 31.6 & 1180 & $1932-2000$ & Lichinga & 13.3 & 35.23 & 1364 & $1951-2003$ \\
\hline Mwinilunga & 11.75 & 24.43 & 1340 & $1950-2002$ & Marrupa & 13.73 & 37.55 & 836 & $1951-1996$ \\
\hline Ndola & 13 & 28.65 & 1280 & $1942-2002$ & Beira_Observatorio & 19.83 & 34.85 & 7 & $1955-1999$ \\
\hline Serenje & 13.23 & 30.22 & 1384 & $1957-2001$ & Tete & 16.18 & 33.58 & 149 & $1952-2005$ \\
\hline Sesheke & 17.47 & 24.3 & 960 & $1950-2002$ & Quelimane & 17.58 & 36.58 & 6 & $1951-2004$ \\
\hline Solwezi & 12.18 & 26.38 & 1400 & $1961-2002$ & Errego_Ile & 16.03 & 37.18 & 533 & $1951-1990$ \\
\hline Zambezi & 13.53 & 23.12 & 1080 & $1953-2002$ & Mapai & 22.06 & 32.05 & 254 & 1956-1999 \\
\hline Mozambique & & & & & Beira Aeroporto & 19.8 & 34.54 & 8 & $1972-2003$ \\
\hline Mocimboa_da_Praia & a 11.35 & 40.37 & 27 & $1951-2005$ & Inhassune & 24.23 & 32.7 & 48 & $1971-1999$ \\
\hline Montepuez & 13.13 & 39.03 & 534 & $1951-2001$ & Manhica_Maragra & 25.45 & 32.8 & 100 & $1970-1997$ \\
\hline Mecufi & 13.28 & 40.57 & 10 & $1951-1991$ & Zimbabwe & & & & \\
\hline Namara_Balama & 13.35 & 38.57 & 597 & 1955-1991 & Harare & 17.83 & 31.02 & 1471 & $1900-2003$ \\
\hline Manjacāe & 24.72 & 33.88 & 65 & 1951-2001 & Bulawayo & 20.15 & 28.51 & 1343 & $1920-2003$ \\
\hline Chibuto & 24.68 & 33.53 & 90 & $1951-2000$ & Kadoma & 18.32 & 29.88 & 1149 & 1951-1993 \\
\hline Macia & 25.03 & 33.1 & 56 & 1951-2002 & Karoi & 16.83 & 29.62 & 1343 & 1951-1990 \\
\hline Xai_Xai & 25.05 & 33.63 & 4 & $1951-2004$ & Kwekwe & 18.93 & 29.83 & 1213 & $1951-2003$ \\
\hline Maniquenique & 24.73 & 33.53 & 13 & $1951-2003$ & Masvingo & 20.07 & 30.87 & 1094 & $1951-2003$ \\
\hline Praia_do_Bilene & 25.45 & 33.25 & 20 & $1958-1999$ & Nyanga & 18.28 & 32.75 & 1878 & $1951-2003$ \\
\hline Chokwe & 24.55 & 33 & 33 & $1961-2004$ & Rusape & 18.37 & 32.13 & 1430 & $1962-1998$ \\
\hline Inhambane & 23.86 & 35.38 & 14 & $1951-2003$ & Beitbridge & 22.22 & 30 & 456 & $1922-2003$ \\
\hline Inharrime & 24.38 & 35.02 & 43 & $1951-2004$ & Gweru & 19.45 & 29.85 & 1428 & $1944-2003$ \\
\hline Morrumbene & 23.67 & 35.37 & 22 & $1951-1996$ & Victoria_Falls & 18.1 & 25.85 & 1061 & $1968-2003$ \\
\hline Nhacoongo & 24.3 & 35.18 & 30 & $1951-1998$ & West_Nicholson & 21.05 & 29.37 & 860 & $1962-1992$ \\
\hline Panda & 24.05 & 34.72 & 150 & $1951-1999$ & Chisengu & 19.88 & 32.88 & 1483 & $1955-2003$ \\
\hline Quissico_Zavala & 24.72 & 34.75 & 147 & $1951-1996$ & Gokwe & 18.22 & 28.93 & 1282 & $1912-2003$ \\
\hline Vilanculos & 22 & 35.32 & 20 & $1951-2001$ & Guruve & 19.45 & 30.7 & 1177 & $1904-2003$ \\
\hline
\end{tabular}

